\title{
Heart-type Fatty acid-binding protein in Acute Myocardial infarction Evaluation (FAME): Background and design of a diagnostic study in primary care
}

\author{
Madeleine HE Bruins Slot*1, Geert JMG van der Heijden ${ }^{1}$, Frans H Rutten ${ }^{1}$, \\ Onno P van der Spoel ${ }^{1}$, E Gijs Mast ${ }^{2}$, Ad C Bredero ${ }^{3}$, Pieter A Doevendans ${ }^{4}$, \\ Jan FC Glatz ${ }^{5}$ and Arno W Hoes ${ }^{1}$
}

Address: ${ }^{1}$ Julius Center for Health Sciences and Primary Care, University Medical Center Utrecht, PO Box 85500, 3508 GA Utrecht, The Netherlands, ${ }^{2}$ St. Antonius Hospital Nieuwegein, Department of Cardiology, 3435 CM Nieuwegein, The Netherlands, ${ }^{3}$ Diakonessenhuis Utrecht, Department of Cardiology, 3582 KE Utrecht, The Netherlands, ${ }^{4}$ Department of Cardiology Division Heart and Lungs, University Medical Center, 3508 GA Utrecht, The Netherlands and ${ }^{5}$ Department of Molecular Genetics, Cardiovascular Research Institute Maastricht (CARIM), Maastricht University, 6200 MD Maastricht, The Netherlands

Email: Madeleine HE Bruins Slot* - m.h.e.bruinsslot@umcutrecht.nl; Geert JMG van der Heijden - g.vanderheijden@umcutrecht.nl; Frans H Rutten - f.h.rutten@umcutrecht.nl; Onno P van der Spoel - o.p.vanderspoel@umcutrecht.nl; E Gijs Mast - e.g.mast@antonius.net; Ad C Bredero - abredero@diakhuis.nl; Pieter A Doevendans - p.doevendans@umcutrecht.nl; Jan FC Glatz - glatz@gen.unimaas.nl; Arno W Hoes - a.w.hoes@umcutrecht.nl

* Corresponding author

Published: 15 April 2008

BMC Cardiovascular Disorders 2008, 8:8 doi:10.1/86/147|-226|-8-8
Received: 13 March 2008

Accepted: 15 April 2008

This article is available from: http://www.biomedcentral.com/I47I-226I/8/8

(C) 2008 Bruins Slot et al; licensee BioMed Central Ltd.

This is an Open Access article distributed under the terms of the Creative Commons Attribution License (http://creativecommons.org/licenses/by/2.0), which permits unrestricted use, distribution, and reproduction in any medium, provided the original work is properly cited.

\begin{abstract}
Background: Currently used biomarkers for cardiac ischemia are elevated in blood plasma after a delay of several hours and therefore unable to detect acute coronary syndrome (ACS) in a very early stage. General practitioners (GPs), however, are often confronted with patients suspected of ACS within hours after onset of complaints. This ongoing study aims to evaluate the added diagnostic value beyond clinical assessment for a rapid bedside test for heart-type fatty-acid binding protein (H-FABP), a biomarker that is detectable as soon as one hour after onset of ischemia.

Methods: Participating GPs perform a blinded H-FABP rapid bedside test (Cardiodetect ${ }^{\circledR}$ ) in patients with symptoms suggestive of ACS such as chest pain or discomfort at rest. All patients, whether referred to hospital or not, undergo electrocardiography (ECG) and venapunction for a plasma troponin test within 12-36 hours after onset of complaints. A final diagnosis will be established by an expert panel consisting of two cardiologists and one general practitioner (blinded to the H-FABP test result), using all available patient information, also including signs and symptoms. The added diagnostic value of the H-FABP test beyond history taking and physical examination will be determined with receiver operating characteristic curves derived from multivariate regression analysis.

Conclusion: Reasons for presenting the design of our study include the prevention of publication bias and unacknowledged alterations in the study aim, design or data-analysis. To our knowledge this study is the first to assess the diagnostic value of H-FABP outside a hospital-setting. Several previous hospital-based studies showed the potential value of H-FABP in diagnosing ACS. Up to now however it is unclear whether these results are equally promising when the test is used in primary care. The first results are expected in the end of 2008.
\end{abstract}




\section{Background}

For a general practitioner (GP), diagnosing or excluding acute coronary syndrome (ACS; comprising unstable angina (UA) and acute myocardial infarction (AMI)) often poses a diagnostic dilemma. On the one hand, missing an ACS may lead to excess morbidity and mortality that could have been prevented with optimal treatment. Guidelines therefore recommend immediate hospital referral in patients suspected of ACS, even when suspicion is relatively low $[1,2]$. On the other hand, unjustified referral of patients without ACS increases workload in the emergency department and causes unnecessary anxiety in both patients and their relatives. Consequently, adequate diagnostic assessment, correctly identifying ACS patients, while limiting unnecessary referral of non-ACS patients is desirable, but may be difficult to achieve.

Although some patients with chest pain or other symptoms suggestive of ACS will contact emergency services directly, the majority of patients will consult a GP first. Typically, the GP will assess these patients using history taking and physical examination only. With these limited tools it is notoriously difficult to accurately rule out or rule in ACS, notably in women and elderly patients in whom signs and symptoms of ACS can be rather atypical [3]. An electrocardiogram (ECG) may provide additional diagnostic information in the assessment of ACS, but is often not available in primary care. Moreover, the initial ECG of a patient with AMI does not always reveal ST-segment elevation or Q-wave changes, indicative of infarction [1]. Alternatively, biomarkers of myocardial damage could be useful as these, after their appearance in plasma, show $100 \%$ sensitivity. Currently, troponin is the biomarker of choice according to European and American guidelines on myocardial infarction. Unfortunately, troponin is elevated only 6-9 hours after onset of ischemia $[1,4,5]$, while most patients with symptoms suggestive of ACS present themselves to the GP between 1 and 3 hours after symptom onset [6-8]; hours before troponin can be used to accurately exclude or confirm AMI.

Recent studies in laboratories and the emergency department have shown that heart-type fatty acid-binding protein (H-FABP), a more recently developed cardiac biomarker, is able to detect myocardial damage as soon as one hour after onset of ischemia and, therefore, is regarded the earliest plasma marker available [9-11]. A bedside test for H-FABP, providing results within 15 minutes [12], could potentially reduce diagnostic uncertainty for patients suspected of ACS in primary care. We therefore sought to determine the diagnostic accuracy and feasibility of a rapid bedside test for H-FABP in patients suspected of ACS in primary care.

\section{Objectives}

This study aims to assess the diagnostic value of a rapid bedside test for H-FABP, in addition to history taking and physical examination in primary care patients suspected of ACS. In addition, the balance between costs and effects of applying the H-FABP bedside test in primary care will be evaluated.

\section{Methods \\ Study design and data collection}

The study design is depicted in figure 1. Patients are primarily recruited by GPs working at one of three participating out-of-hours GP services in the region of Utrecht, The Netherlands (1 urban and 2 semi-urban). Additionally, 25 GPs from group practices will recruit patients during daytime hours. Diagnostic assessment during the initial GP consultation includes standardised history taking and physical examination and rapid H-FABP testing (see below). To allow for a definitive decision whether ACS is present ("gold" or reference standard) an ECG is recorded and a venous blood sample is collected in all patients (for measurement of currently preferred biomarkers including troponin, creatinin kinase (CK) and creatinin kinasemyocardial band (CK-MB)), irrespective of whether or not they are referred to hospital. In patients who are referred to hospital these measurements are performed as part of routine care. Patients who are not referred to hospital are visited at home by qualified GP laboratory service personnel to perform the above mentioned tests. Blood samples are obtained between 12 to 36 hours after onset of complaints in order to allow for a definitive diagnosis of AMI. Using this time interval we adopt a safe margin for a troponin rise to become detectable in the blood.

The study protocol was approved by the Medical Ethics Committee of the University Medical Center Utrecht, The Netherlands.

\section{In- and exclusion criteria}

All patients with symptoms suggestive of ACS who present themselves to a GP are eligible for inclusion in the study. Presenting symptoms will typically include chest pain or discomfort at rest, but also atypical "vague" complaints such as abdominal discomfort, dizziness or sudden onset of dyspnoea.

Excluded are patients with complaints lasting more than 24 hours, as H-FABP levels usually return to normal 2436 hours after onset of myocardial ischemia [9,11]. Also excluded are patients who require instant hospital referral and those patients in whom no written informed consent is obtained. 


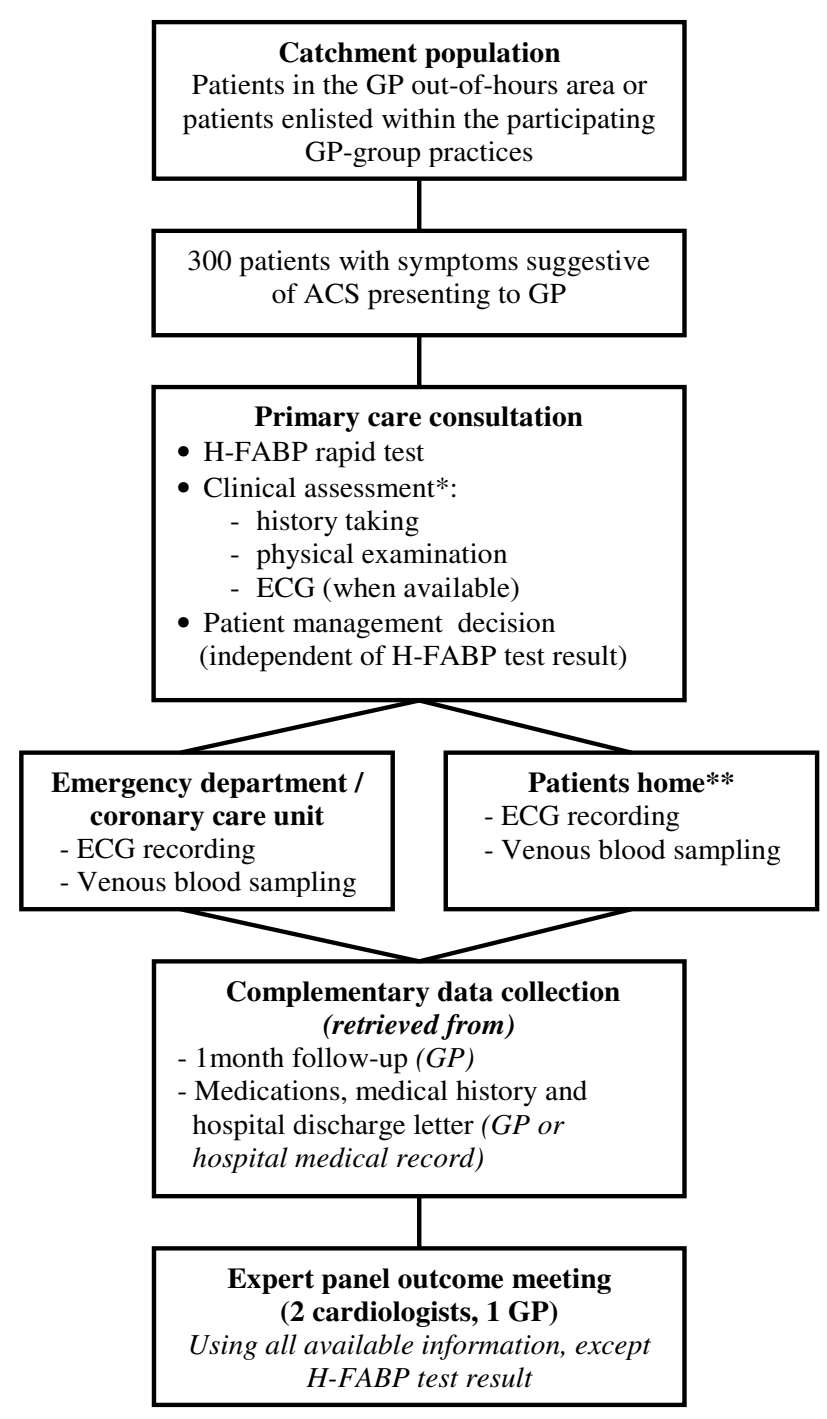

Figure I

Flow diagram of study design. Abbreviations: GP = general practitioner, ACS = acute coronary syndrome, H-FABP = heart-type fatty acid-binding protein, ECG = electrocardiogram. * The clinical score is based on ref. 13. ** Measurements are performed by qualified GP laboratory personnel.

\section{H-FABP test and clinical score}

The H-FABP bedside test (Cardiodetect ${ }^{\circledR}$ Rennesens $\mathrm{GmbH}$, Berlin) can easily be performed by the GP by drawing four drops of capillary whole blood from the patient's finger and applying them onto the test-strip. Within 15 minutes the H-FABP test result (elevated or non-elevated plasma FABP) is available. For study purposes the result is concealed by a blinding-strip. The test is de-blinded by the GP after he/she has made the referral decision. Test results are documented on a standardized case record form, together with findings from history tak- ing and physical examination. Other items on the form include age, gender, prior AMI and treatment for AMI (bypass surgery or percutaneous coronary intervention). Also recorded are patient delay and doctor delay and a probability estimate by the GPs (prior to the H-FABP test result) that a patient has ACS, their decision about referral to hospital and the result of the H-FABP test.

A previous study by Grijseels et al provided a pre-hospital decision rule based on items from history taking and physical examination for patients suspected of ACS [13]. We will validate the diagnostic accuracy of this clinical score and estimate the added value of the H-FABP bedside test.

\section{Outcome}

An expert panel consisting of two cardiologists and one GP will establish the final diagnosis using all available patient information, including signs and symptoms, ECG and biomarker levels (troponin-T or -I, CK and CK-MB). These results are available for all patients, including patients that are not referred to hospital, as they are visited at home by qualified GP laboratory personnel for performance of ECG and laboratory tests.

AMI will be defined in accordance with guidelines from the European Society of Cardiology and the American College of Cardiology [1,5] The diagnosis of AMI is established when patients have suggestive symptoms (such as chest pain) and a maximal concentration of troponin $\mathrm{T}$ or I exceeding the decision limit (99 $9^{\text {th }}$ percentile of the values for a reference control group) within the first 36 hours after the onset of complaints and/or CK-MB values greater than two times the upper reference limit on at least one occasion during the same time frame. The presence of STand T-wave changes on the ECG, notably ST elevations and Q-waves, can further confirm AMI. Unstable angina (UA) is defined as symptoms of chest pain and ST- and/or T-wave changes on the ECG suggestive of ischemia, without elevation of troponin or CK-MB above the decision limits $[1,5]$.

\section{Patient management}

As already mentioned, every GP will decide about referral to hospital in accordance with daily practice, using only history taking and physical examination and, when available, ECG. This decision is made without using the HFABP test result. For safety reasons an exception is made for patients with a positive H-FABP test result in whom the GP initially decided not to refer. In these cases, the GP is instructed to change his initial management decision in favor of hospital referral. 


\section{Statistical analyses}

Using 2 by 2 tables the diagnostic value of the H-FABP test alone and in combination with the clinical score will be assessed, using AMI as the outcome, and positive and negative predictive values, sensitivity and specificity will be calculated with 95\% confidence interval.

Multivariable regression analysis with receiver operating characteristic (ROC) curves will be used to determine whether the H-FABP test provides added diagnostic value beyond history taking and physical examination (summarized in a clinical score). Two diagnostic models will be tested: one using only the clinical score, the other one consisting of the clinical score together with the H-FABP test result. This will lead to 2 different areas under the ROC-curve (AUC), where the difference in AUC presents the added value of the H-FABP test.

As AMI is notoriously difficult to diagnose in women and the elderly we will perform subgroup analyses in these specific patient categories [1].

\section{Sample size and power calculation}

A frequently used 'rule of thumb' recommends that for each diagnostic determinant included in a multivariable logistic regression analysis at least 10 events (in this case AMI) are necessary $[15,16]$. Our study includes 2 diagnostic determinants (clinical score and H-FABP test result). Thus, a population in which at least 20 patients with AMI is required. Although available estimates vary, Dutch studies show that in more than $10 \%$ of patients suspected of AMI by the GP the diagnosis is confirmed [2,13]. Therefore, 200 patients with suspected AMI need to be included in our study. We will include 300 patients to allow for subgroup analyses.

\section{Design issues \\ Blinding}

In diagnostic prediction research the physician ideally should be blinded to the results of the test under study in order to prevent bias in the ascertainment of the disease. In this study, the H-FABP test result may influence the inferences drawn from medical history and physical examination, and thereby influence the referral decision of the GP, especially since it is notoriously difficult to decide about the presence or absence of an ACS based on clinical assessment only.

There are however two important reasons why a fully blinded H-FABP test is not feasible in our study. Firstly, previous hospital based studies showed that the H-FABP bedside test has a positive predictive value of well above $80 \%$ [17-20]. We therefore instructed the GPs to decide on the referral before de-blinding the test result, but for safety reasons we also instructed them to refer patients with a positive $\mathrm{H}$-FABP test result to hospital irrespective of their initial referral decision. Secondly, in the hours following application of the test, discoloration of the teststrip occurs which negatively influences the interpretation and thereby the accuracy of the test results. Therefore the test has to be read shortly after its performance.

\section{Informed consent}

It is neither very realistic nor feasible to ask written informed consent to study participation from a patient in an acute life threatening situation, such as with symptoms suggestive for ACS. Therefore the Medical Ethics Committee agreed to ask verbal consent from patients for taking the H-FABP test by the GP. Subsequently patients are given the opportunity for written informed consent after having read an information letter at a more convenient moment. Patients may also decide to withdraw their consent then or at any time thereafter. Only patients who return a written informed consent are included in our study.

\section{Recruitment}

We have chosen for a phased introduction of our study in 3 different GP out-of-hour services (weekdays from 5 pm8 am and weekends). Participating centers are notified of the study progress by a monthly overview of the number of participants and a 2-monthly newsletter with background information on the study, frequently asked questions and tips and tricks, for instance on how to draw the required amount of capillary blood. We anticipate including 300 patients within 36 months.

\section{Preliminary Results}

In March 2006 we started enrollment of patients. In September 2007, 172 patients were included; i.e. monthly enrollment of about 12 patients. Conclusion of enrollment is anticipated before the summer of 2008. Baseline characteristics of the first participants are summarized in Table 1.

\section{Discussion}

The presentation of the design of our study provides the reader the opportunity to get informed about our study in an early stage. Moreover, publishing the design of a study independently of its results allows for a reflection on the design of a study. It helps to reduce publication bias and unacknowledged alterations in the study aims, the study design or data-analysis during its conduct. Finally, this article can be seen as an announcement of upcoming study results that may have an impact on the guidelines on acute coronary syndrome currently used in primary care.

Our study on H-FABP as a new cardiac biomarker is noteworthy as patients are recruited outside a hospital setting. 
Table I: Preliminary patient baseline characteristics $(\mathbf{N}=172)$

\begin{tabular}{lc}
\hline & Number (\%) \\
\hline Demographics & \\
Age (years, mean \pm SD) & $66 \pm 14$ \\
$\geq 75$ years & $57(33)$ \\
Female & $88(51)$ \\
Risk factors $(\mathrm{N}=114)$ & \\
$\quad$ Current smoker & $21(22)$ \\
Diabetes mellitus & $24(21)$ \\
Hypertension & $51(45)$ \\
Hyperlipidemia & $36(32)$ \\
Prior ischemic heart disease & $34(30)$ \\
Presenting symptoms & \\
Chest pain & $157(91)$ \\
Radiation of chest pain & $109(64)$ \\
Vagal symptoms* & $97(57)$ \\
Patient referred to hospital & $126(73)$ \\
Duration of symptoms (hours) ${ }^{*}$ & $3.0($ IQR I.4-7.0) \\
\hline
\end{tabular}

* Including nausea, sweating, pallor

** From symptom onset until time of testing, IQR = interquartile range

The, few, previous studies on H-FABP have been performed in the emergency room or by ambulance personnel [17-23], representing an entirely different domain of patients than those seen by the GP. This is also illustrated by the difference in prevalence of AMI in these populations. Hospital-based studies reported a prevalence of AMI around or above $50 \%$ in those suspected of AMI [17$21,24]$, with the exception of one study that reported a prevalence of $16 \%$ [22]. Studies performed in primary care observed prevalences as low as 5 or $8 \%[13,25]$. By definition this difference in prevalence has an important impact on the added diagnostic value of the novel rapid bedside test.

Many (earlier) diagnostic studies focus on the performance of a single test, ignoring the information obtained from history taking and physical examination. Based on symptoms and signs however, the likelihood of ACS may increase or decrease, thereby potentially altering the added value of the test. Moreover, single test research is not according to clinical practice, where a diagnosis is established after multiple tests performed in a hierarchical way, starting with simple, non-invasive and inexpensive tests, such as signs and symptoms [26]. Therefore a clinical score based on history and physical examination is included in our diagnostic model and the added value of the H-FABP bedside test will be calculated.

Previous studies with H-FABP in the hospital-setting showed the potential value of this novel cardiac biomarker in assessing patients suspected of ACS. Since GPs are confronted with patients suspected of an acute coronary syndrome at a very early stage, mostly without the availa- bility of an ECG, the impact of a novel cardiac biomarker on the diagnostic assessment is potentially much higher in general practice than in the emergency room. To answer the question whether H-FABP has (additional) diagnostic value in the diagnosis of ACS in the primary care setting, the test needs to be studied before its introduction in that specific setting.

Application of an early biomarker potentially reduces diagnostic uncertainty in patients suspected of an ACS. On the one hand this may lead to a reduction of unnecessary hospital referrals, patient burden, hospital work load and health care costs. On the other hand, a diagnosis of ACS can be established much earlier than with troponin which may result in earlier initiation of treatment, including revascularization interventions.

To our knowledge, our study is the first to assess the (added) diagnostic value of H-FABP in patients with chest pain or other complaints suggestive of ACS in primary care.

\section{Competing interests}

The study was supported by a grant from the Netherlands Organisation for Health Research and Development (ZonMw grant 945-06-009). Test panels were provided by Clindia Benelux BV, Leusden, the Netherlands. All authors are fully independent from the funder.

\section{Authors' contributions}

All authors contributed to the conception and design of the study. MHEBS, FHR and GJMGH drafted the manuscript. FHR, EGM and ACB also participated in the outcome panel meetings. All authors read and approved the final draft of the manuscript.

\section{Acknowledgements}

We thank all personnel from SALTRO Doctor Laboratory (Utrecht, The Netherlands) for all their patient visits and data collection. We thank Dr. A Mosterd, cardiologist (Meander Medical Center Amersfoort, the Netherlands) for his participation in the outcome panel meetings. We are very grateful to $L$ Vendrig, KE Menninga, $M$ de Leeuw and $G$ van Hemert (Julius Center for Health Sciences and Primary Care) for their contribution in the data collection. Furthermore, we thank all GPs and personnel from participating out of hours GP services (Zeist, Houten and Nieuwegein; The Netherlands) and GP practices (Zeist, Houten, Nieuwegein, IJsselstein, De Bilt, Bilthoven, Wijk bij Duurstede; The Netherlands).

\section{References}

I. Bassand JP, Hamm CW, Ardissino D, Boersma E, Budaj A, FernandezAviles F, Fox KA, Hasdai D, Ohman EM, Wallentin L, Wijns W, Vahanian A, Camm J, De CR, Dean V, Dickstein K, Filippatos G, Kristensen SD, Widimsky P, McGregor K, Sechtem U, Tendera M, Hellemans I, Gomez JL, Silber S, Funck-Brentano C, Kristensen SD, Andreotti F, Benzer W, Bertrand M, Betriu A, De CR, Desutter J, Falk V, Ortiz AF, Gitt A, Hasin Y, Huber K, Kornowski R, Lopez-Sendon J, Morais J, Nordrehaug JE, Silber S, Steg PG, Thygesen K, Tubaro M, Turpie AG, Verheugt $F$, Windecker S: Guidelines for the diagnosis and treatment of non-ST-segment elevation acute coronary syn- 
dromes: The Task Force for the Diagnosis and Treatment of Non-ST-Segment Elevation Acute Coronary Syndromes of the European Society of Cardiology. Eur Heart J 2007, 28: $1598-1660$

2. Rutten FH, Grundmeijer HGLM, Grijseels EWM, Van Bentum STB, Hendrick JMA, Bouma M, et al.: NHG-standaard Acuut coronair syndroom (Acuut myocardinfarct en instabiele angina pectoris). Huisarts Wet 2003, 46:83I-843.

3. Culic V, Eterovic D, Miric D, Silic N: Symptom presentation of acute myocardial infarction: influence of sex, age, and risk factors. Am Heart J 2002, 144:1012-1017.

4. Myocardial infarction redefined--a consensus document of The Joint European Society of Cardiology/American College of Cardiology Committee for the redefinition of myocardial infarction. Eur Heart / 2000, 21:1502-1513.

5. Anderson JL, Adams CD, Antman EM, Bridges CR, Califf RM, Casey DE Jr., Chavey WE, Fesmire FM, Hochman JS, Levin TN, Lincoff AM, Peterson ED, Theroux P, Wenger NK, Wright RS, Smith SC Jr. Jacobs AK, Adams CD, Anderson JL, Antman EM, Halperin JL, Hunt SA, Krumholz HM, Kushner FG, Lytle BW, Nishimura R, Ornato JP, Page RL, Riegel B: ACC/AHA 2007 guidelines for the management of patients with unstable angina/non-ST-Elevation myocardial infarction: a report of the American College of Cardiology/American Heart Association Task Force on Practice Guidelines (Writing Committee to Revise the 2002 Guidelines for the Management of Patients With Unstable Angina/Non-ST-Elevation Myocardial Infarction) developed in collaboration with the American College of Emergency Physicians, the Society for Cardiovascular Angiography and Interventions, and the Society of Thoracic Surgeons endorsed by the American Association of Cardiovascular and Pulmonary Rehabilitation and the Society for Academic Emergency Medicine. J Am Coll Cardiol 2007, 50:el-el 57.

6. Bleeker IK, Simoons ML, Erdman RA, Leenders CM, Kruyssen HA, Lamers LM, van der DE: Patient and doctor delay in acute myocardial infarction: a study in Rotterdam, The Netherlands. $\mathrm{Br}$ J Gen Pract 1995, 45: I8I-184.

7. Broer J, Bleeker JK, Bouma J, de Jongste MJ, Erdman RA, Meyboomde JB: [Regional differences in prehospital time delay for patients with acute myocardial infarction; Rotterdam and Groningen, 1990-1995]. Ned Tijdschr Geneeskd 2000, 144:78-83.

8. Hitchcock T, Rossouw F, McCoubrie D, Meek S: Observational study of prehospital delays in patients with chest pain. Emerg Med J 2003, 20:270-273.

9. Glatz JF, van der Vusse GJ, Simoons ML, Kragten JA, van DieijenVisser MP, Hermens WT: Fatty acid-binding protein and the early detection of acute myocardial infarction. Clin Chim Acta 1998, 272:87-92.

10. van Nieuwenhoven FA, Kleine AH, Wodzig WH, Hermens WT, Kragten HA, Maessen JG, Punt CD, Van Dieijen MP, van V, Glatz JF: Discrimination between myocardial and skeletal muscle injury by assessment of the plasma ratio of myoglobin over fatty acid-binding protein. Circulation 1995, 92:2848-2854.

II. Pelsers MM, Hermens WT, Glatz JF: Fatty acid-binding proteins as plasma markers of tissue injury. Clin Chim Acta 2005, 352: $15-35$

12. Chan CP, Sum KW, Cheung KY, Glatz JF, Sanderson JE, Hempel A Lehmann M, Renneberg I, Renneberg R: Development of a quantitative lateral-flow assay for rapid detection of fatty acidbinding protein. J Immunol Methods 2003, 279:91-100.

13. Grijseels EW, Deckers JW, Hoes AW, Boersma E, Hartman JA, van der DE, Simoons ML: Implementation of a pre-hospital decision rule in general practice. Triage of patients with suspected myocardial infarction. Eur Heart J 1996, 17:89-95.

14. Braunwald E, Antman EM, Beasley JW, Califf RM, Cheitlin MD, Hochman JS, Jones RH, Kereiakes D, Kupersmith J, Levin TN, Pepine CJ, Schaeffer JW, Smith EE III, Steward DE, Theroux P, Alpert JS, Eagle KA, Faxon DP, Fuster V, Gardner TJ, Gregoratos G, Russell RO, Smith SC Jr.: ACCIAHA guidelines for the management of patients with unstable angina and non-ST-segment elevation myocardial infarction. A report of the American College of Cardiology/American Heart Association Task Force on Practice Guidelines (Committee on the Management of Patients With Unstable Angina). J Am Coll Cardiol 2000, 36:970-1062.
15. Concato J, Peduzzi P, Holford TR, Feinstein AR: Importance of events per independent variable in proportional hazards analysis. I. Background, goals, and general strategy. J Clin Epidemiol 1995, 48: | 495-I50I.

16. Peduzzi P, Concato J, Feinstein AR, Holford TR: Importance of events per independent variable in proportional hazards regression analysis. II. Accuracy and precision of regression estimates. J Clin Epidemiol 1995, 48: I503-15I0.

17. Ishii J, Wang JH, Naruse $H$, Taga S, Kinoshita M, Kurokawa $H$, Iwase M, Kondo T, Nomura M, Nagamura Y, Watanabe Y, Hishida H, Tanaka $T$, Kawamura K: Serum concentrations of myoglobin vs human heart-type cytoplasmic fatty acid-binding protein in early detection of acute myocardial infarction. Clin Chem 1997, 43:1372-1378.

18. Okamoto F, Sohmiya K, Ohkaru Y, Kawamura K, Asayama K, Kimura H, Nishimura S, Ishii H, Sunahara N, Tanaka T: Human heart-type cytoplasmic fatty acid-binding protein (H-FABP) for the diagnosis of acute myocardial infarction. Clinical evaluation of H-FABP in comparison with myoglobin and creatine kinase isoenzyme MB. Clin Chem Lab Med 2000, 38:23I-238.

19. Nakata T, Hashimoto A, Hase M, Tsuchihashi K, Shimamoto K: Human heart-type fatty acid-binding protein as an early diagnostic and prognostic marker in acute coronary syndrome. Cardiology 2003, 99:96-104.

20. Ecollan P, Collet JP, Boon G, Tanguy ML, Fievet ML, Haas R, Bertho N, Siami S, Hubert JC, Coriat P, Montalescot G: Pre-hospital detection of acute myocardial infarction with ultra-rapid human fatty acid-binding protein (H-FABP) immunoassay. Int J Cardiol 2007, I I 9:349-354.

21. Seino Y, Ogata K, Takano T, Ishii J, Hishida H, Morita H, Takeshita H, Takagi $Y$, Sugiyama $H$, Tanaka T, Kitaura $Y$ : Use of a whole blood rapid panel test for heart-type fatty acid-binding protein in patients with acute chest pain: comparison with rapid troponin T and myoglobin tests. Am J Med 2003, I I 5: 185-190.

22. Haastrup B, Gill S, Kristensen SR, Jorgensen PJ, Glatz JF, Haghfelt T, Horder M: Biochemical markers of ischaemia for the early identification of acute myocardial infarction without St segment elevation. Cardiology 2000, 94:254-261.

23. Mad P, Domanovits H, Fazelnia C, Stiassny K, Russmuller G, Cseh A Sodeck G, Binder T, Christ G, Szekeres T, Laggner A, Herkner H: Human heart-type fatty-acid-binding protein as a point-ofcare test in the early diagnosis of acute myocardial infarction. QJM 2007, 100:203-210.

24. Seino Y, Tomita Y, Takano T, Ohbayashi K: Office cardiologists cooperative study on whole blood rapid panel tests in patients with suspicious acute myocardial infarction: comparison between heart-type fatty acid-binding protein and troponin T tests. Circ J 2004, 68: I44- | 48.

25. Nilsson S, Scheike M, Engblom D, Karlsson LG, Molstad S, Akerlind I, Ortoft K, Nylander E: Chest pain and ischaemic heart disease in primary care. Br J Gen Pract 2003, 53:378-382.

26. Moons KG, Grobbee DE: Diagnostic studies as multivariable, prediction research. J Epidemiol Community Health 2002, 56:337-338.

\section{Pre-publication history}

The pre-publication history for this paper can be accessed here:

http://www.biomedcentral.com/1471-2261/8/8/prepub 